\title{
Copy number variation of PRAMEY across breeds and its association with male fertility in Holstein sires
}

\author{
X. P. Yue, ${ }^{*} †$ T. C. Chang, ${ }^{* 1}$ J. M. DeJarnette, $\ddagger$ C. E. Marshall, $\ddagger$ C. Z. Lei, $†$ and W.-S. Liu*2 \\ *Department of Animal Science, The Center for Reproductive Biology and Health (CRBH), College of Agricultural Sciences, \\ The Pennsylvania State University, University Park 16802 \\ †College of Animal Science and Technology, Northwest A\&F University, Yangling, Shaanxi, 712100, P.R. China \\ $\ddagger$ Select Sires Inc., Plain City, OH 43064
}

\begin{abstract}
Multi-copy gene families are especially prevalent in the male-specific region (MSY) of the mammalian Y chromosome. Copy number variations (CNV) of these Y-linked gene families have been shown to affect human and animal fertility. The PRAMEY (Preferentially expressed antigen in melanoma, Y-linked) gene family is a newly identified, bovid-specific Y-linked gene family, which codes for a cancer/testis antigen that is expressed predominantly in testis and various tumors. The PRAMEY gene family is believed to play an important role in spermatogenesis and male fertility in cattle. The objective of this study was to investigate the CNV of PRAMEY within and across breeds and to determine whether CNV was associated with reproductive traits in Holstein bulls. A quantitative real-time PCR method was applied to measure the copy number of PRAMEY among 460 bulls using a Y-linked single copy gene, DDX3Y (DEAD box polypeptide 3, Y-linked), as a reference. The median copy number of PRAMEY was 13, ranging from 2 to 31 . Significant variations in PRAMEY copy number were observed among 15 breeds investigated. Holstein bulls had the lowest median copy number (12), whereas Limousin bulls possessed the highest median copy number (26). Furthermore, bulls in the taurine lineage (13) had a significantly lower median copy number than those bulls in the indicine lineage (20). Association analysis revealed that PRAMEY copy number was correlated negatively with scrotal circumference (SC), relative scrotal circumference (RLSC), percentage of normal sperm (PNS), and nonreturn rate (NRR), but had no significant association with postthaw motility (PTM), incubated motility (IM), percentage of intact acrosome (PIA), sire conception rate (SCR), or relative breeding efficiency (RBE). The data from this

\footnotetext{
Received May 16, 2013.

Accepted August 19, 2013.

${ }^{1}$ Present address: Department of Plant Pathology, University of

${ }^{2}$ Corresponding author: wul12@psu.edu
} California Davis, Davis 95616
\end{abstract}

study indicate that $\mathrm{CNV}$ of the PRAMEY gene family is associated with male reproductive traits and may serve as a valuable marker for sire fertility selection at an early age in cattle.

Key words: PRAMEY, copy number variation, $\mathrm{Y}$ chromosome, bull fertility

\section{INTRODUCTION}

Genomic selection has been applied in cattle breeding programs to accelerate genetic gain for traits such as milk production (VanRaden et al., 2009) and meat quality (Mannen, 2011). However, limited opportunities exist for genetic improvement through genomic selection of semen quality and male fertility traits, partly because of the lack of molecular studies on male fertility. The Y chromosome is present in males only and carries several testis-specific genes that play fundamental roles in spermatogenesis and male fertility (Lahn and Page, 1997, 1999; Lahn et al., 2001; Cocquet et al., 2009; Reynard et al., 2009; Chang et al., 2011a; Yang et al., 2011). Recent progress in sequencing and structure analysis of the human (Skaletsky et al., 2003), mouse (Alföldi, 2008), and bovine Y chromosomes (Chang et al., 2013) has identified at least 3 types of sequence variations, including SNP, insertion/deletion (indel), and copy number variation $(\mathbf{C N V})$, which provide an opportunity to develop genetic markers for male reproduction evaluation. Of particular interest is the deletion or $\mathrm{CNV}$ of the Y-linked multi-copy gene families that are all expressed predominantly or solely in testis (Skaletsky et al., 2003; Chang et al., 2013). In mice, deletions of Y-linked multi-copy genes, such as Sly (Sycp3-like Y-linked), affect spermatogenesis, with the most extensive deletions resulting in severe sperm-head malformations and infertility (Cocquet et al., 2009; Reynard et al., 2009). In humans, deletions (or microdeletions) in the $A Z F a-c$ (Azoospermia factor $\mathrm{a}, \mathrm{b}, \mathrm{c}$ ) regions on the long arm of the human $\mathrm{Y}$ are the most frequent genetic cause of severe oligozoospermia and azoospermia (Krausz et al., 2003; Krausz, 2005), accounting for 10 to $18 \%$ of men with spermatogenic 
Table 1. Bull information and the median copy number of PRAMEY in 15 cattle breeds

\begin{tabular}{lccl}
\hline Breed & $\begin{array}{c}\text { No. of } \\
\text { bulls }\end{array}$ & $\begin{array}{c}\text { Median (range) } \\
\text { copy number }\end{array}$ & Lineage \\
\hline Angus & 14 & $17(16-21)$ & Bos taurus \\
Beefmaster & 14 & $17(13-24)$ & Taurine/indicine \\
Brahman & 10 & $19(9-31)$ & Bos indicus \\
Brown Swiss & 14 & $20(14-27)$ & Bos taurus \\
Charolais & 10 & $21(15-27)$ & Bos taurus \\
Gir & 14 & $20(19-21)$ & Bos indicus \\
Hereford & $15^{1}$ & $17(11-19)$ & Bos taurus \\
Holstein & 257 & $12(2-20)$ & Bos taurus \\
Jersey & 28 & $14(10-23)$ & Bos taurus \\
Limousin & 14 & $26(3-30)$ & Bos taurus \\
Nelore & 10 & $25(24-26)$ & Bos indicus \\
Norwegian Red & 9 & $14(8-16)$ & Bos taurus \\
Qinchuan (Bos indicus) & 10 & $14(7-16)$ & Bos indicus \\
Qinchuan (Bos taurus) & 16 & $16(11-30)$ & Bos taurus \\
Red Angus & 11 & $15(12-20)$ & Bos taurus \\
Santa Gertrudis & 14 & $24(20-25)$ & Taurine/indicine \\
Total or median & 460 & $13(2-31)$ & \\
\hline
\end{tabular}

${ }^{1}$ The bull used as the calibrator was not used for the median copy number estimation for the Hereford breed.

failure (Foresta et al., 2001; Kleiman et al., 2003; Krausz and Degl'Innocenti, 2006; Poongothai et al., 2009). Copy number variations of Y-linked multi-copy gene families, such as $D A Z$ (Deleted in azoospermia) and TSPY (Testis-specific protein, Y-encoded), have been found to be associated with semen quality (Vodicka et al., 2007; Giachini et al., 2009) and reproduction in men (Lin et al., 2005).

The gene content of the bovine $\mathrm{Y}$ has been recently studied and at least 6 multi-copy, protein-coding gene families, including TSPY, HSFY (Heat-shock transcription factor, Y-linked), and $P R A M E Y$, were identified (Chang et al., 2013). Both TSPY and HSFY have been analyzed with respect to their CNV in cattle (Hamilton et al., 2009, 2011, 2012). The CNV of TSPY is positively correlated with bull fertility and negatively correlated with gene expression level (Hamilton et al., 2012). A similar approach was applied to examine the copy number of $H S F Y$, although no variation was observed in the initial report (Hamilton et al., 2011).

The PRAME (Preferentially expressed antigen in melanoma) gene is a member of the cancer/testis antigens that are expressed predominantly in normal testis and in a variety of tumors (Chang et al., 2011a); PRAME is believed to play important roles in immunity and reproduction (Kastner et al., 1996; Epping et al., 2005; Ortmann et al., 2008; Chang et al., 2011a). It is one of the most amplified gene families in Eutherian mammals, with approximately 90 copies in the mouse, 50 copies in the human, and 30 copies in the bovine genomes (Birtle et al., 2005; Church et al., 2009; Chang et al., 2011a). The PRAMEY (PRAME, Y-linked) gene is a bovid-specific Y-chromosome gene originating from transposition of an autosomal PRAME paralog on BTA17 and amplified on the Y chromosome during evolution (Chang et al., 2011a; Yang et al., 2011). The PRAMEY gene is expressed specifically in testis (Chang et al., 2011a), with the sense RNA of PRAMEY expressed specifically in spermatids and the antisense RNA expressed in all cell types in the seminiferous tubules. The highest expression is reported to occur in spermatids, suggesting that it plays an important role in spermatogenesis (Chang et al., 2011a). A recent study on mouse Pramel1 (Prame-like 1), an ortholog of PRAME/PRAMEY, indicated that Pramel1 is involved in acrosome formation and sperm motility (Mistry et al., 2013). Approximately 10 copies of PRAMEY are present in the $\mathrm{Y}$ chromosome (based on the draft sequence) of the bull whose DNA was used for the bovine Y sequence project (Chang et al., 2011a, 2013). However, it is unclear whether the copy number of PRAMEY varies between individual males and among cattle breeds. The objective of this study was to determine the CNV of PRAMEY in different cattle breeds and to test whether the CNV was associated with reproductive traits in Holstein bulls.

\section{MATERIALS AND METHODS}

\section{Phenotype and Pedigree of Animals and DNA Preparation}

A total of 460 bulls from 15 breeds were used in this study (Table 1). Semen samples were collected from 257 Holstein bulls that had phenotypic records and pedigree information. The remaining animals were either from the bovine HapMap Project (13 breeds; Gibbs et al., 2009) or from a Chinese local cattle breed 
(Qinchuan), which did not have any phenotypic records or pedigree information. A Hereford bull L1 Domino 99375 (American Hereford Association registration number 41170496) was sequenced in the bovine $\mathrm{Y}$ chromosome sequencing project (https://www.hgsc. bcm.edu/content/y-chromosome-genome-project) and was used as a calibrator. This bull is the sire of the cow L1 Dominette 01449, whose DNA was sequenced in the bovine genome sequence project. Semen DNA was extracted using Qiagen DNeasy blood and tissue kit (Qiagen, Valencia, CA) according to manufacturer's instructions.

Of the 257 Holstein bulls that were used in AI, 140 had records for scrotal circumference (SC), age-adjusted relative scrotal circumference (RLSC), postthaw motility (PTM), incubated motility (IM), percentage of normal sperm (PNS), and percentage of intact acrosome (PIA). In addition, 82 (of these 140) bulls had data on sire conception rate (SCR), which is a bull fertility evaluation system recently developed by the US Department of Agriculture (http://aipl.arsusda.gov/ reference/arr-scr1.htm), and 102 (of the 140) bulls had data on relative breeding efficiency (RBE), an in-house bull fertility evaluation parameter estimated by Select Sires Inc. (Plain City, OH). Relative breeding efficiency uses a similar methodology to SCR but contains only a 1-yr rolling database (Amann and DeJarnette, 2012). The remaining 117 Holstein bulls had data on nonreturn rate (NRR), a fertility parameter used by Semex Alliance (Guelph, ON, Canada). Nonreturn rate is a traditional methodology to evaluate bull fertility, indicating that a cow was inseminated and was not called to re-service within a given amount of time (usually 60 d) for the first service (Amann and DeJarnette, 2012). Data for the paternal pedigrees of the Holstein bulls were collected from the public databases, including the US Department of Agriculture-Animal Improvement Programs Laboratory (Beltsville, MD; http:// aipl.arsusda.gov/) and the Holstein Association USA (Brattleboro, VT; http://www.holsteinusa.com).

\section{Primer Design}

The PRAMEY sequence (GenBank accession no. GU144301) was aligned to the bovine Y chromosome draft sequence assembly (GenBank accession no. CM001061, NCBI Project ID: 20275) using Splign (Kapustin et al., 2008). Ten PRAMEY loci were predicted and the paralogous sequences were retrieved and aligned by MEGA 5.0 (Tamura et al., 2011). The PCR primers were designed from conserved regions, based on the alignment of PRAMEY sequences, using the Primer Premier 5.0 program (http://www. premierbiosoft.com/). A single-copy gene DDX3Y (DEAD box polypeptide 3, Y-linked; GenBank accession no. NT182066) was used as reference. The primer sequences were as follows: PRAMEY: forward, 5'-GCCCATCCTGTGCCCCTGCT-3'; reverse, 5'-CTCCCTCCCCGCCCACTCTA-3' and DDX3Y: forward, 5'-ATCGTGGGCGGAATGAGTGT-3'; reverse, 5'-CTTGGTGGAAGCGGTTTTGA-3'. To confirm the $\mathrm{Y}$ chromosome-specificity of the designed primers, a routine PCR was performed using male and female cattle genomic DNA as templates and water as a negative control. The PCR protocol was as follows: each $20-\mu \mathrm{L}$ reaction contained $13.76 \mu \mathrm{L}$ of distilled water, $0.5 \mu \mathrm{L}$ of each primer $(10 \mathrm{pmol} / \mu \mathrm{L}), 4 \mu \mathrm{L}$ of Bioline $5 \times$ buffer (Bioline USA Inc., Taunton, MA, including $200 \mu M$ deoxyribonucleotide triphosphates), $0.24 \mu \mathrm{L}$ of Bioline Taq DNA polymerase (Bioline USA Inc.), and $1 \mu \mathrm{L}$ of either genomic DNA $(10 \mathrm{ng} / \mu \mathrm{L})$ or water. Thermocycling consisted of an initial denaturation at $95^{\circ} \mathrm{C}$ for $5 \mathrm{~min}$, followed by 35 cycles of at $94^{\circ} \mathrm{C}$ for 30 $\mathrm{s}$, at $65^{\circ} \mathrm{C}$ for $30 \mathrm{~s}$, and at $72^{\circ} \mathrm{C}$ for $30 \mathrm{~s}$, and a final extension at $72^{\circ} \mathrm{C}$ for $5 \mathrm{~min}$.

\section{Quantitative Real-Time PCR}

Quantitative real-time PCR (qPCR) was used to measure the copy number of PRAMEY in the samples using the 7900HT Fast Real-Time PCR System and Power SYBR Green PCR Master Mix kit (Invitrogen, Carlsbad, CA). Plates with 384 wells were set up to run the qPCR. On each plate, we set up wells for standard curve samples, a calibrator (i.e., bull L1 Domino 99375), and a negative control (distilled water). Standard curves were generated from bovine DNA diluted to $12.5,5,2.5,0.5$, and $0.1 \mathrm{ng} / \mu \mathrm{L}$ for both PRAMEY and $D D X 3 Y$ primers. For the test bull samples, DNA was concentrated to $5 \mathrm{ng} / \mu \mathrm{L}$. A PCR with standard curve samples was run in triplicate, and remaining test samples (including calibrator and negative control) were run in duplicate. In this study, we ran a total of 460 bulls on 6 plates (each plate was set up for 1 calibrator plus 87 testing samples). Each reaction contained $5 \mu \mathrm{L}$ of SYBR Green PCR Master Mix, $0.5 \mu \mathrm{L}$ of primers $(10 \mathrm{pmol} / \mu \mathrm{L}), 3 \mu \mathrm{L}$ of distilled water, and $1 \mu \mathrm{L}$ of DNA template $(5 \mathrm{ng} / \mu \mathrm{L})$. The $\mathrm{qPCR}$ was run with a program of the following steps: predenaturation at $95^{\circ} \mathrm{C}$ for $10 \mathrm{~min}$, followed by 45 cycles of denaturation at $95^{\circ} \mathrm{C}$ for $15 \mathrm{~s}$, annealing at $65^{\circ} \mathrm{C}$ for $30 \mathrm{~s}$, and extension at $72^{\circ} \mathrm{C}$ for $30 \mathrm{~s}$; final extension at $72^{\circ} \mathrm{C}$ for $5 \mathrm{~min}$. A melting curve was then generated by taking fluorescent measurements every $0.1^{\circ} \mathrm{C}$ from $60^{\circ} \mathrm{C}$ until $95^{\circ} \mathrm{C}$. The resulting reactions had an efficiency of 1.95 and 1.92 for PRAMEY and DDX3Y, respectively, according to the equation $\mathrm{E}=10^{-1 / \text { slope }}$. 


\section{Copy Number Estimation}

The copy number of PRAMEY was estimated for test samples by using the following 3 equations described in Hamilton et al. (2009):

$$
\begin{aligned}
& \text { Copy number } r_{\text {calibrator }}=\frac{\left(\mathrm{E}_{\text {reference }}\right)^{\mathrm{C}_{\mathrm{T}_{\text {reference }}}}}{\left(\mathrm{E}_{\text {target }}\right)^{\mathrm{C}_{\mathrm{T}_{\text {target }}}}}, \\
& \text { Ratio }=\frac{\left(\mathrm{E}_{\text {target }}\right)^{\left.\Delta \mathrm{C}_{\mathrm{T}_{\text {target }}} \text { (calibrator - sample }\right)}}{\left(\mathrm{E}_{\text {reference }}\right)^{\Delta \mathrm{C}_{\mathrm{T}_{\text {reference }}} \text { (calibrator - sample) }}}, \\
& \text { Copy number } \mathrm{r}_{\text {test sample }}= \\
& (\text { copy number } \text { calibrator }) \times(\text { ratio }) \text {. }
\end{aligned}
$$

In the above equations, the DNA sample of the Hereford bull L1 Domino 99375 was used as the calibrator. The cycle threshold $\left(\mathbf{C}_{\mathbf{T}}\right)$ value of the calibrator for each gene (PRAMEY and DDX3Y) was determined by the average of $12 \mathrm{C}_{\mathrm{T}}$ values obtained in 6 different plates for this particular sample; $\mathrm{E}=$ the PCR efficiency for either PRAMEY (1.95) or DDX3Y (1.92); and $\Delta \mathrm{C}_{\mathrm{T}}=$ $\mathrm{C}_{\mathrm{T}}$ of the calibrator $-\mathrm{C}_{\mathrm{T}}$ of the test sample.

\section{Association and Statistical Analysis}

To minimize the technical impact and to have an accurate copy number estimation, raw qPCR data that showed a coefficient of variation $>1 \%$ between the duplicates were excluded from further analysis (a total of 35 bulls were eliminated in this study). The normality of the PRAMEY copy number data was assessed with the Kolmogorov-Smirnov and Shapiro-Wilk normality tests (Shapiro and Wilk, 1965; Justel et al., 1997). The multiple pairwise comparison of the PRAMEY median copy number between breeds was analyzed using a nonparametric Mann-Whitney U test (Mann and Whitney, 1947) with a Bonferroni correction (Dunn, 1961). In addition, the Mann-Whitney U test was used to compare the median copy number between groups that were classified based on the origin and formation of the cattle breeds: Bos taurus (BTA), Bos indicus (BIN), and composite (COM), and those groups that were classified into high fertility (NRR $\geq 70 \%$ ), low fertility $(55 \leq \mathrm{NRR} \leq 62 \%)$, and subfertility $(\mathrm{NRR}<55 \%)$ based on their NRR records.

Association analyses of the PRAMEY copy number with the fertility traits (see above) were performed only in the Holstein bulls by using a Pearson correlation test using SPSS 17.0 software (SPSS Inc., Chicago, IL). A 2-way ANOVA was applied to investigate the effect of the PRAMEY copy number and the founder (of a paternal pedigree) on SC, RLSC, PTM, IM, PNS, and PIA using a general linear model in SPSS 17.0. Furthermore, a mixed model in SAS 9.2 (SAS Institute Inc., Cary, NC) was applied to investigate the effect of CNV of PRAMEY on RLSC, SC, PTM, IM, PNS, and PIA, in which the sire was included as a random effect. A $P$-value $<0.05$ was considered statistically significant for each test.

\section{CNV of PRAMEY Across Cattle Breeds}

Before the qPCR analysis, we first validated the male specificity of the PRAMEY and DDX $3 Y$ primers by a routine PCR. As shown in Figure 1, both PRAMEY and $D D X 3 Y$ primers amplified a male-specific band of the expected size, confirming that the DNA fragments were amplified from the corresponding genes on the bovine Y chromosome, not from the autosomal ortho$\log (P R A M E)$ or the X-linked DDX3X (DEAD box polypeptide 3 , X-linked).

The copy number of PRAMEY in the calibrator was estimated to be 13 using Equation [1] (see Materials and Methods). Subsequently, the gene copy number of testing bulls was calculated using the calibrator as adjustment based on Equations [2] and [3] (see Materials and Methods), and the results are summarized in Table 1. The median copy number of PRAMEY was 13 , ranging from 2 to 31 among the bulls tested. Statistical analysis indicated significant CNV among these animals $(P<0.001)$. Interestingly, copy number data did not fit the normal distribution $(P<0.05)$ in either the Holstein population (the largest population, with 257 AI bulls) in the study (Figure 2A, Table 1) or all populations in the 15 breeds tested (Figure 2B). The distribution of copy number in the Holstein population

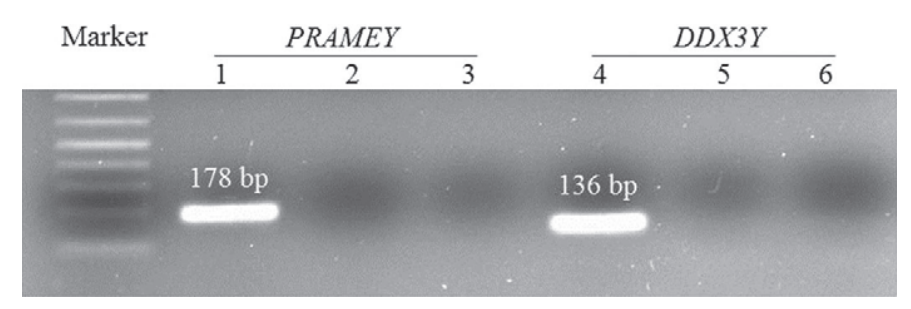

Figure 1. Gel electrophoresis of PCR products of the bovine $P R A M E Y$ and DDX3Y genes. Marker = 1-kb DNA ladder; lane 1: PRAMEY PCR product amplified from the Hereford bull L1 Domino 99375 genomic DNA (187 bp); lane 2: PRAMEY PCR product amplified from female cattle genomic DNA; lane 3: negative control (distilled water) for PRAMEY; lane 4: DDX3Y PCR product amplified from the Hereford bull L1 Domino 99375 genomic DNA (136 bp); lane 5: DDX3Y PCR product amplified from female cattle genomic DNA; lane 6: negative control (distilled water) for $D D X 3 Y$. 
showed 2 obvious peaks, one at a copy number of 11 and the other at 13 (Figure 2A).

The pairwise comparisons of the median copy number between breeds are listed in Table 2 and indicated a significant difference among breeds $(P<0.05)$. Holstein bulls had the lowest median copy number of PRAMEY (12, range: 2-20), whereas Limousin bulls possessed the highest (26, range: $3-30)$, which was sig-
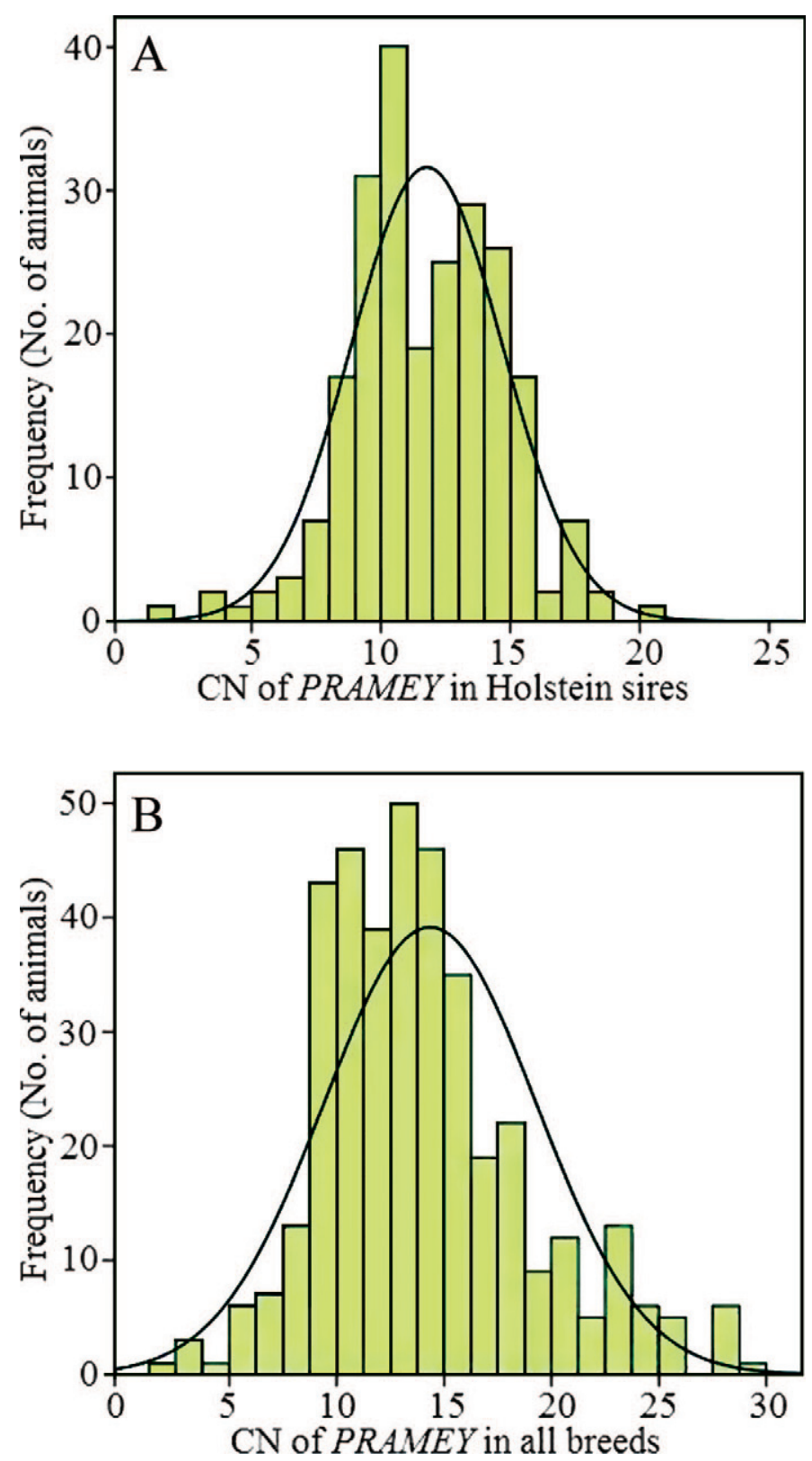

Figure 2. Distribution of the PRAMEY copy number $(\mathrm{CN})$ in the bulls. (A) Distribution of PRAMEY CN among 257 Holstein bulls; (B) distribution of the PRAMEY CN among all 460 bulls analyzed; the $\mathrm{CN}$ data do not fit the normal distribution based on the KolmogorovSmirnov and Shapiro-Wilk normality tests. Color version available in the online PDF. nificantly higher than that of the Holstein bulls $(P<$ 0.001). Furthermore, bulls in the taurine (BTA) lineage had significantly lower median copy number (13) than bulls in the indicine (BIN) lineage (20), whereas the 3 composite cattle breeds (Beefmaster, Santa Gertrudis, and Qinchuan) had intermediate median copy numbers of 17 (Figure 3).

In the present study, we analyzed 26 bulls from a population of Qinchuan, a native Chinese composite cattle in central China. Based on a previous Y-chromosome SNP haplotype analysis, 16 of 26 Qinchuan bulls had a BTA Y chromosome, and the remaining 10 had a BIN Y chromosome (Chang et al., 2011b). It was interesting to note that Qinchuan bulls with a BTA-derived Y chromosome had a significantly $(P<$ 0.01) higher median copy number of PRAMEY (16) than those bulls with a BIN-derived Y chromosome (14; Table 2, Figure 3).

\section{Association of PRAMEY CNV with Male Reproductive Traits in Holstein Bulls}

To determine the relationship between PRAMEY CNV and male reproductive traits, we analyzed the CNV in 257 Holstein AI bulls by Pearson correlation analyses. We focused our association analysis on 3 types of male reproductive traits: testis size, semen quality, and a general fertility measurement. For testis size, we evaluated 2 traits, SC and RLSC (the latter being an age-adjusted SC). Our results revealed that the CNV of PRAMEY was negatively correlated with both SC (r $=-0.26, P=0.003)$ and RLSC $(\mathrm{r}=-0.27, P=0.002)$ (Figure 4A, B), indicating that a lower copy number of $P R A M E Y$ is associated with a larger testis size.

For the semen quality parameters, we analyzed PTM, IM, PNS, and PIA. Associations of CNV with the semen quality parameters were not significant in PTM (r $=-0.08, P=0.36)$, IM $(\mathrm{r}=-0.05, P=0.60)$, or PIA $(\mathrm{r}=0.03, P=0.73)$, but the association between the CNV of PRAMEY and PNS tended toward significance $(\mathrm{r}=-0.16, P=0.09$; Figure $4 \mathrm{C})$.

For the general fertility measurement, we analyzed 3 traits: SCR, RBE, and NRR. The results demonstrated that the CNV of PRAMEY was negatively correlated with NRR ( $\mathrm{r}=-0.38, P<0.001)$, suggesting that a lower copy number of $P R A M E Y$ was associated with a higher NRR (Figure 4D). In addition, we did pairwise comparisons of the median copy number of PRAMEY between the high fertility (NRR $\geq 70 \%$ ), low fertility $(55 \% \leq \mathrm{NRR} \leq 62 \%)$, and subfertility (NRR <55\%) groups and found that the high NRR group had a significantly lower median copy number $(P<0.05$; Figure $3)$. Association analyses of the PRAMEY copy number with RBE $(\mathrm{r}=0, P=0.88)$ and SCR $(\mathrm{r}=0.06, P$ 
Table 2. Comparisons of the copy number of PRAMEY among 15 cattle breeds ${ }^{1,2}$

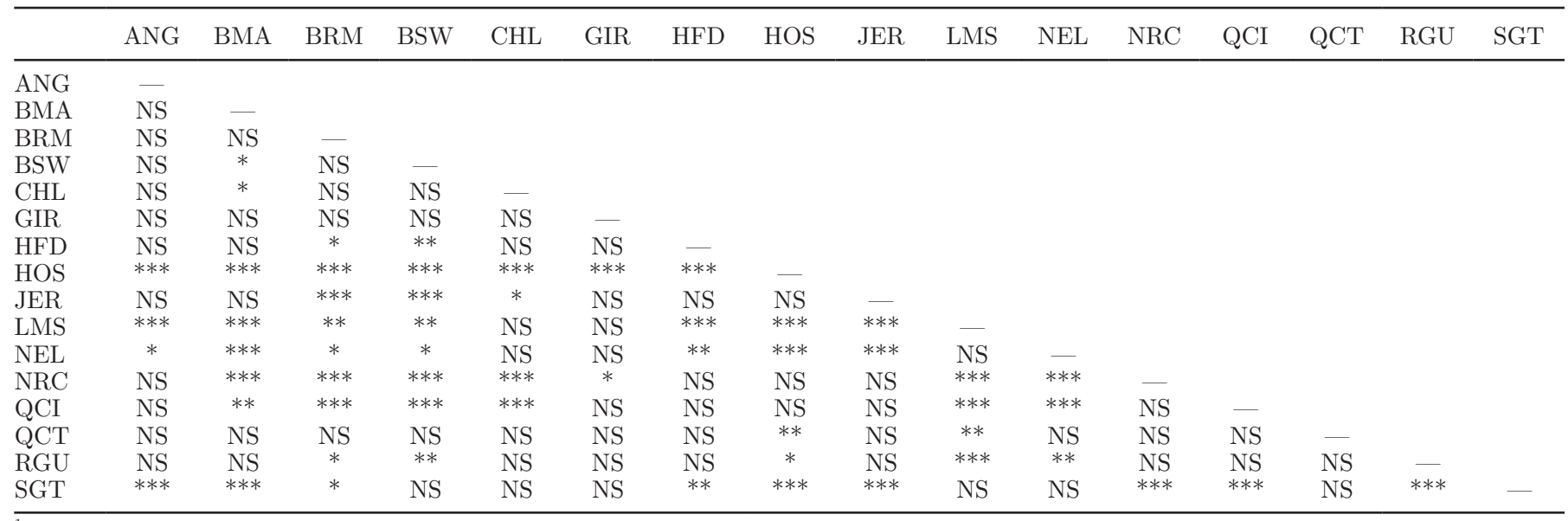

${ }^{1}$ The pairwise comparisons were analyzed by a Mann-Whitney U test with a Bonferroni correction.

${ }^{2} \mathrm{ANG}=$ Angus; BMA = Beefmaster; BRM = Brahman; BSW = Brown Swiss; CHL = Charolais; GIR = Gir; HFD = Hereford; HOS = Holstein; JER = Jersey; LMS = Limousin; NEL = Nelore; NRC = Norwegian Red; QCI = Qinchuan (Bos indicus); QCT = Qinchuan (Bos taurus); RGU $=$ Red Angus; SGT $=$ Santa Gertrudis.

${ }^{*} P<0.05 ; * * P<0.01 ;{ }^{* * *} P<0.001$.

$=0.62)$ were also performed, although no significant associations were found.

As mentioned above, 2 peaks of median copy number were observed in the Holstein population (Figure 2A), which were also reflected in the PRAMEY copy number plot analysis in Figure 4A-C. To test whether the genotype (copy number distribution) is associated with the phenotype (bull reproductive traits), we simply divided

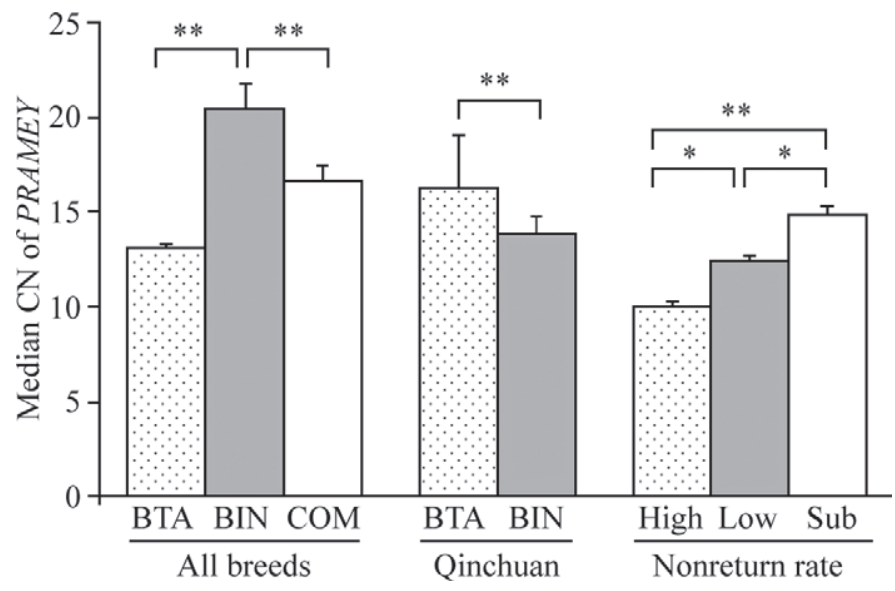

Figure 3. Comparison of the copy number (CN) of PRAMEY among Bos taurus (BTA), Bos indicus (BIN), and composite (COM) lineages and among different groups of nonreturn rate (NRR; high fertility, low fertility, and subfertility). The CN of PRAMEY was significantly different between the lineages $(P<0.01)$. In the Qinchuan cattle, the median CN of PRAMEY in BTA-derived bulls was significantly higher than that in BIN-derived bulls $(P<0.01)$. In addition, The CN was significantly different among the high NRR, low NRR, and subfertile groups $(P<0.01)$. These comparisons were assessed by a nonparametric Mann-Whitney $\mathrm{U}$ test. The error bars represent standard errors; ${ }^{*} P<0.05 ;{ }^{* *} P<0.01$. these 140 Holstein bulls into 2 groups based upon genotype (copy number of PRAMEY): Group I (68 bulls) had copy numbers $<12$, and group II (72 bulls) had copy numbers $\geq 12$ (Figure $4 \mathrm{~A}-\mathrm{C}$ ). The reproductive performance of the 2 groups of bulls is listed in Table 3. Statistical analysis (one-way ANOVA) indicated that the difference between the 2 groups was significant for SC $(P=0.008)$, RLSC $(P=0.01)$, and PNS $(P$ $=0.02)$, but not significant in the remaining 3 traits (PTM, IM, and PIA; $P>0.05$; Table 3). These results, from a different angle, confirmed that the copy number of PRAMEY is associated with the bull fertility.

\section{Relationship Between Holstein Bull Pedigrees and Their PRAMEY CNV and Reproductive Traits}

We were able to collect and analyze pedigree data for a total of 192 Holstein bulls from public databases (see Materials and Methods). Of these, 94 bulls were half-sib brothers from 27 sires (families), with the largest family having 11 members. To exclude the sire effect from the PRAMEY CNV association analyses, we included sire in the mixed model as a random effect. We found that the CNV of PRAMEY had a significant effect on SC $(P=0.04)$ and RLSC $(P=0.05)$, and the effect of the PRAMEY copy number tended to be significant on PNS $(P=0.09)$, indicating that PRAMEY is an important gene involved in male reproduction.

Because AI has been widely used in the dairy industry since the 1960s, we looked further at the Y-pedigree information for all bulls in this study. We found that all the animals were descendants of only 4 patrilineal founders (HOUSA1427381, HOUSA1428104, HOU- 
Table 3. Reproductive performance of Holstein bulls grouped by copy number of PRAMEY

\begin{tabular}{|c|c|c|c|c|c|}
\hline \multirow{2}{*}{$\begin{array}{l}\text { Reproductive } \\
\text { trait }^{2}\end{array}$} & \multicolumn{2}{|c|}{ Group I (copy number <12) } & \multicolumn{2}{|c|}{ Group II (copy number $\geq 12$ ) } & \multirow[b]{2}{*}{$P$-value } \\
\hline & No. of bulls & Mean $\pm \mathrm{SE}$ & No. of bulls & Mean $\pm \mathrm{SE}$ & \\
\hline $\mathrm{SC}(\mathrm{cm})$ & 68 & $40.7 \pm 0.4$ & 72 & $39.0 \pm 0.5$ & 0.008 \\
\hline RLSC (\%) & 68 & $100.9 \pm 0.9$ & 72 & $97.6 \pm 0.8$ & 0.01 \\
\hline PNS (\%) & 68 & $80.2 \pm 0.9$ & 72 & $78.0 \pm 0.9$ & 0.02 \\
\hline PTM (\%) & 68 & $77.8 \pm 0.3$ & 72 & $77.6 \pm 0.4$ & 0.30 \\
\hline IM (\%) & 68 & $34.2 \pm 0.3$ & 72 & $33.9 \pm 0.5$ & 0.55 \\
\hline PIA (\%) & 68 & $80.2 \pm 0.4$ & 72 & $80.3 \pm 0.4$ & 0.86 \\
\hline
\end{tabular}

${ }^{1}$ The comparison was conducted by a one-way ANOVA.

${ }^{2} \mathrm{SC}=$ scrotal circumference; RLSC = relative scrotal circumference; PNS = percentage of normal sperm; PTM $=$ postthaw motility; IM = incubated motility; PIA = percentage of intact acrosome.

SA1441440, and HOUSA1491007) that were born in the 1960s. The median copy number of PRAMEY for each founder lineage was recalculated (Supplemental Figure S1; http://dx.doi.org/10.3168/jds.2013-7037).
Although the median copy number varied between these lineages, the variations were not significant $(P$ $>0.05$ ). The HOUSA1427381 (median copy number $=10.7$ ) and HOUSA1441440 (10.5) founders shared
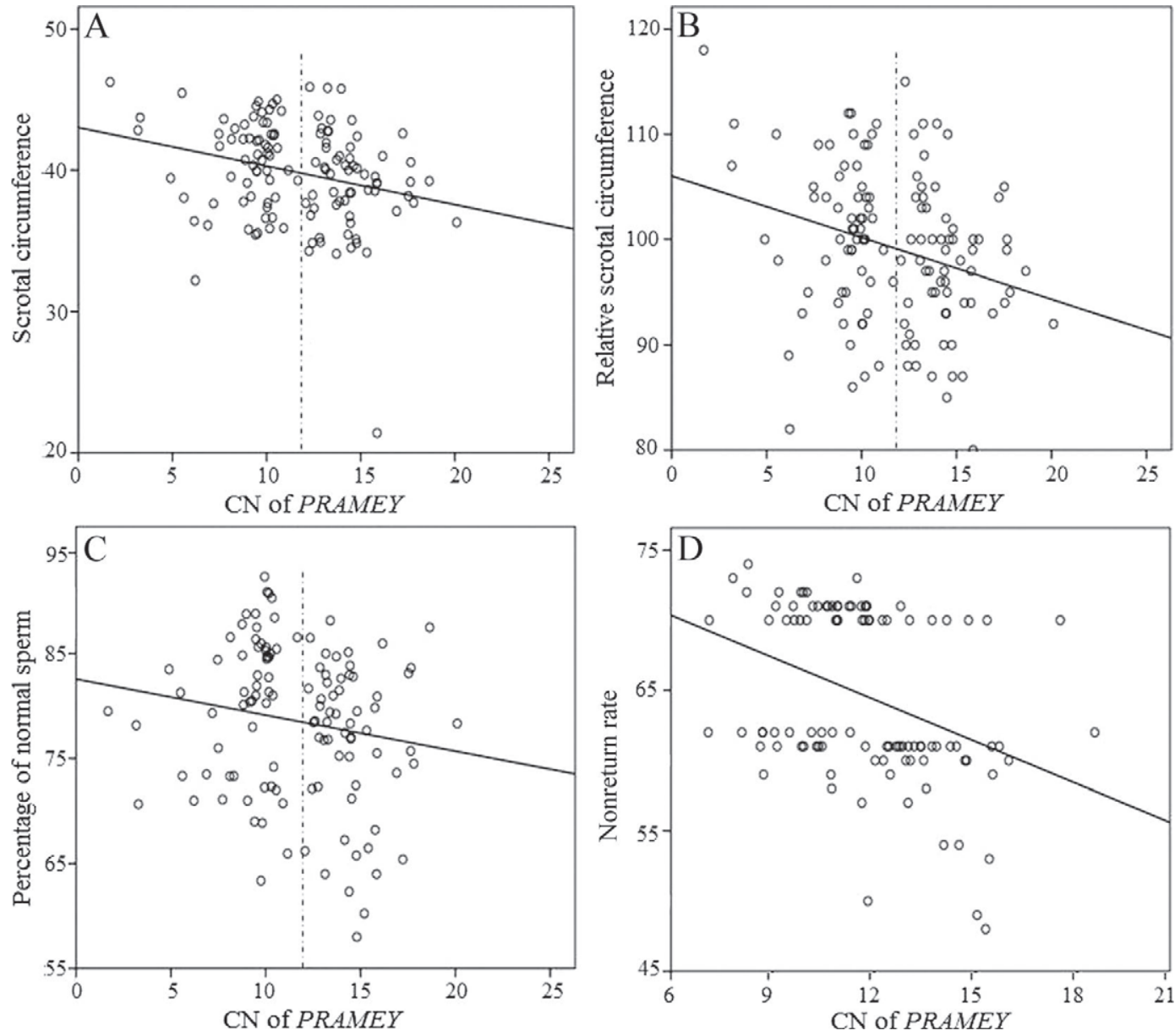

Figure 4. Correlations between copy number $(\mathrm{CN})$ variation of $P R A M E Y$ and bull reproductive traits. The association of the PRAMEY CNV with bull reproductive traits was conducted by the Pearson correlation analysis. The PRAMEY CNV was negatively associated with (A) scrotal circumference $(\mathrm{r}=-0.26, P=0.003),(\mathrm{B})$ relative scrotal circumference $(\mathrm{r}=-0.27, P=0.002)$, $(\mathrm{C})$ percentage of normal sperm $(\mathrm{r}=$ $-0.16, P=0.087)$, and $(\mathrm{D})$ nonreturn rate $(\mathrm{r}=-0.38, P<0.001)$. Each circle represents one individual. The vertical dashed line in panels A, $\mathrm{B}$, and $\mathrm{C}$ marks the cut-off threshold $(\mathrm{CN}=12)$ that was used to divided the tested animals into 2 groups based on their genotypes. 
the same ancestor going back to 1860 and their median copy numbers were very similar, whereas founder HOUSA1491007 had a relatively higher median copy number of 12.4, reflecting the evolutionary relics of the paternal Y chromosome lineages.

To test whether the association between the PRAMEY $\mathrm{CNV}$ with male reproductive traits observed above for the entire Holstein population was still present in the different paternal lineages, we performed 2-way ANOVA with data from 2 founders, HOUSA1427381 and HOUSA1491007, in which a relatively large number (40 and 81) of descendants were included in this study. The results revealed that copy number had a significant effect on SC $(P=0.01)$ and $\operatorname{RLSC}(P=0.02)$ in both Y-lineages, whereas pedigree had a significant effect only on PTM $(P=0.02$; Table 4$)$. In addition, we observed a significant interaction between pedigree and PRAMEY copy number on the reproductive traits of $\operatorname{PTM}(P=0.007)$, PNS $(P=0.04)$ and PIA $(P=0.03)$.

\section{DISCUSSION}

In the present study, we investigated the CNV of the PRAMEY gene family by a qPCR method modified from Hamilton et al. (2009). The modified method took the advantage of the bovine $\mathrm{Y}$ chromosome draft sequence assembly for PCR primer design to target all PRAMEY-related loci on Y. Because genomic DNA from the bull L1 Domino 99375, which was used for the Y chromosome sequence project, was available to us, we decided to use this animal as a calibrator to minimize the technical variations between PCR plates during the estimation of the PRAMEY copy number. We used this sequenced animal rather than a randomly selected unsequenced animal as the calibrator to better facilitate comparisons of our results to similar studies in the future. We observed that the PRAMEY copy number was 13 for the calibrator in all PCR plates we run, which was different from the 10 copies in the assembled

Table 4. The effect of the PRAMEY copy number and the founder on reproductive traits as indicated by $P$-values in ANOVA ${ }^{1}$

\begin{tabular}{lccc}
\hline $\begin{array}{l}\text { Reproductive } \\
\text { trait }^{2}\end{array}$ & Founder & $\begin{array}{c}\text { PRAMEY } \\
\text { copy number }\end{array}$ & $\begin{array}{c}\text { Founder } \times \\
\text { copy number }\end{array}$ \\
\hline SC & 0.18 & 0.01 & 0.78 \\
RLSC & 0.09 & 0.02 & 0.69 \\
PNS & 0.96 & 0.06 & 0.04 \\
PTM & 0.02 & 0.32 & 0.007 \\
IM & 0.32 & 0.71 & 0.18 \\
PIA & 0.44 & 0.36 & 0.03 \\
\hline
\end{tabular}

${ }^{1} \mathrm{~A}$ two-way ANOVA was run in a general linear model.

${ }^{2} \mathrm{SC}=$ scrotal circumference; $\mathrm{RLSC}=$ relative scrotal circumference; PNS = percentage of normal sperm; PTM = postthaw motility; IM = incubated motility; PIA = percentage of intact acrosome. draft sequence of the same $\mathrm{Y}$ chromosome (Chang et al., 2011a). This difference is most likely caused by the unfinished Y chromosome sequence assembly in which 2 gaps $(\sim 0.5 \mathrm{Mb} /$ gap $)$ are located adjacent to either side of a narrow region where the PRAMEY loci are located (Chang et al., 2013).

Previous studies indicated that the bovine Y-linked TSPY gene family has been extensively amplified (50200 copies $)$ across the entire ampliconic region $(\sim 30$ $\mathrm{Mb}$ ) during evolution (Hamilton et al., 2009; Chang et al., 2013), whereas the "autosome-to-Y" transposed $P R A M E Y$ gene family is less amplified in a $5-\mathrm{Mb}$ region located in a so-called transitional region between the pseudoautosomal and ampliconic regions on the bovine Y chromosome (Chang et al., 2013). The data from the current study confirm that the PRAMEY gene family is less amplified, with a median PRAMEY copy number of 13 across breeds. However, we found that the PRAMEY copy number was highly variable among the 460 individuals and 15 cattle breeds investigated. Importantly, PRAMEY CNV was also significantly different between the BTA and BIN lineages (Table 1). We found that BTA-derived bulls demonstrated a significantly lower median copy number than bulls in the BIN lineage. Although the reason for this is unclear, Y morphology is different between BTA and BIN at the cytogenetic level. The Y chromosome of taurine bulls is submetacentric, whereas it is acrocentric in indicine bulls (Goldammer et al., 1997). This morphological difference is believed to be caused by a chromosome rearrangement (Meo et al., 2005). However, it is still unknown whether this rearrangement event is associated with the amplification or expansion of PRAMEY or any other Y-linked genes. It is worth noting that the range of the PRAMEY copy number in BIN (9-31) overlapped with the range observed in the BTA lineage (2-30), although the BIN breeds (Brahman, Gir, and Nelore) showed a higher median copy number (17) than the BTA breeds (13; Table 1$)$. In addition, the Chinese native breed, Qinchuan, whose Y is known to be derived either from BTA or from BIN (Chang et al., 2011b), showed the opposite pattern, with the BTAderived individuals having a significantly higher median copy number of PRAMEY than the BIN-derived individuals; both groups of Qinchuan bulls, however, had relatively low median copy numbers (15 and 13). Furthermore, our pedigree analysis on the Holstein AI bulls identified the difference in the median copy number of PRAMEY between the patrilineal ( $\mathrm{Y}$ chromosome) lineages. Together, these results suggest that the CNV of the PRAMEY gene family was influenced by breeding and selection during the formation of a cattle breed, in addition to the evolutionary forces that led to the formation of BTA and BIN lineages. Given 
the fact that the male-specific region (i.e., $95 \%$ of the $\mathrm{Y}$ chromosome) where PRAMEY is located does not recombine during meiosis and any variation (including the CNV) we observed from a patrilineal lineage is an evolutionary relic of that particular Y-chromosome lineage, our data suggest that the ancestor or founder effect will be maintained for many generations.

The relationship between CNV of Y-linked genes and male fertility has been tested in humans and cattle. In humans, an early report found that a significantly higher copy number of TSPY was detected in infertile men (Vodicka et al., 2007), whereas another study found a significant positive correlation between the CNV of TSPY and sperm count (Giachini et al., 2009), and a subsequent study found no relationship between the CNV of TSPY and semen quality (Nickkholgh et al., 2010). These conflicting results were due mainly to biases in study design (Krausz et al., 2010). In cattle, the CNV of TSPY was found to be positively correlated with solution index (a modified NRR; Hamilton et al., 2012). In the present study, we found that the CNV of PRAMEY was negatively associated with testis size, PNS, and NRR, suggesting that a bull with a lower copy number of PRAMEY tends to have larger testes and higher PNS and NRR. It was surprising to observe that the CNV of PRAMEY was significantly associated with NRR but not with SCR and RBE. This discrepancy might be explained by the fact that these 3 traits were derived from 3 different fertility evaluation systems (for details, visit http://aipl.arsusda.gov/ reference/arr-scr1.htm). Although these evaluation systems have the same objective (to improve the male fertility), they may not measure the genetic effects of the same group of (fertility-related) genes because of the use of the different sets of phenotypic data (http:// aipl.arsusda.gov/reference/arr-scr1.htm).

Even though the association analysis performed in the present study was limited to the Holstein breed, we think our general conclusion (that a bull with a lower copy number of PRAMEY has higher fertility) may apply to other cattle breeds. This is supported by findings of a previous study to compare male fertility among BTA breeds, which found that Limousin and Charolais were among the worst breeds in terms of fertility (Berry et al., 2011). Indeed, Limousin and Charolais had the highest median copy numbers of PRAMEY among all BTA breeds we investigated in this study (Table 1). In terms of reproductive performance between BTA and BIN lineages, a few previous studies have demonstrated that BTA breeds had significantly better sperm quality than BIN breeds (Brito et al., 2002; Beletti et al., 2005), which coincides with our discovery that the BTA lineage had a lower median copy number of PRAMEY than the BIN lineage.
Why is a low copy number of PRAMEY advantageous for bull fertility? The molecular mechanism behind this is unknown. Our previous study indicated that all copies of PRAMEY on the Y chromosome are transcriptionally active (Chang et al., 2011a). However, whether or not a higher or lower copy number of PRAMEY affects the transcription and translation of this gene family (as a whole) has not yet been studied. It has been reported that CNV of several genes are negatively associated with their expression level (Stranger et al., 2007; Schuster-Böckler et al., 2010), and the excessive copy number of the human TSPY could negatively regulate cell division in the process of spermatogenesis (Vodicka et al., 2007).

It is worth noting that PRAMEY, unlike the other Y-linked genes that have no or only a few autosomal paralogs, has approximately 30 copies of autosomal paralogs in the bovine genome (based on the sequenced cow), which may also play an important role in male reproduction (Chang et al., 2011a). A recent study revealed that Pramel1, an ortholog of PRAME, is involved in acrosome formation and sperm motility in the mouse (Mistry et al., 2013). It is our prediction that, just like the Y-linked PRAMEY family, the copy number of autosomal PRAME genes likely varies between individuals and among breeds. Because there is low sequence similarity of the PRAME family in the autosome $(\sim 50 \%)$, it is impossible for us to design common primers for the qPCR method, which prevented us from investigating the CNV of autosomal PRAME genes in this study. Other methods - for instance, comparative genomic hybridization or next-generation sequencingcould be applied to investigate the CNV of autosomal PRAME in the future.

Testicular size is a unique trait for a bull and has been used as a predictive indicator for output of sperm cells for yearling bulls (Parkinson, 2004). It has been estimated that for every 1-cm increase in a sire's SC over the population average, one can expect a $0.25-\mathrm{cm}$ increase in SC in male offspring due to a moderate (0.4) to high (0.7) heritability (Coulter and Foote, 1976; Coulter et al., 1987). However, testicular size, like other reproduction traits, cannot be used for early sire selection (newborn to 8 mo old). To date, knowledge about the molecular basis of SC is very limited. Development of genetic markers, such as the CNV of PRAMEY identified in this work, could facilitate earlier prediction of testis size and male fertility (at the newborn stage) and accelerate genetic improvement for male fertility traits.

\section{CONCLUSIONS}

The copy number of PRAMEY was found to be variable among individuals and breeds in cattle. The copy 
number of PRAMEY was negatively associated with testis size, percentage of normal sperm, and nonreturn rate in Holsteins; it may serve as a potential marker for sire fertility selection at an early age in cattle.

\section{ACKNOWLEDGMENTS}

We thank Select Sires Inc. (Plain City, $\mathrm{OH}$ ) and Semex Alliance (Guelph, ON, Canada) for providing bull semen samples and phenotypic records. We are grateful to Chad Dechow (Department of Animal Science, Pennsylvania State University, University Park) and Huanmin Zhang (USDA, ARS Avian Disease and Oncology Laboratory, East Lansing, MI) for their advice on the statistical analysis and comments on the manuscript and to Leeson J. Alexander (USDA, ARS Fort Keogh Livestock and Range Research Laboratory, Miles City, MT) and Clare Gill (Department of Animal Science, Texas A\&M University, College Station) for sharing DNA samples of the Hereford bull L1 Domino 99375 and of bulls used in the Bovine HapMap Project. We also thank the two anonymous reviewers for their comments to improve the manuscript. This project was supported by a grant (no. 2010-65205-20362) from the National Institute of Food and Agriculture of the US Department of Agriculture (Washington, DC) and a research grant from Select Sires to WSL.

\section{REFERENCES}

Alföldi, J. E. 2008. Sequence of the Mouse Y Chromosome. Massachusetts Institute of Technology, Cambridge, MA.

Amann, R. P., and J. M. DeJarnette. 2012. Impact of genomic selection of AI dairy sires on their likely utilization and methods to estimate fertility: A paradigm shift. Theriogenology 77:795-817.

Beletti, M. E., L. da F. Costa, and M. P. Viana. 2005. A comparison of morphometric characteristics of sperm from fertile Bos taurus and Bos indicus bulls in Brazil. Anim. Reprod. Sci. 85:105-116.

Berry, D. P., R. D. Evans, and S. Mc Parland. 2011. Evaluation of bull fertility in dairy and beef cattle using cow field data. Theriogenology $75: 172-181$.

Birtle, Z., L. Goodstadt, and C. Ponting. 2005. Duplication and positive selection among hominin-specific PRAME genes. BMC Genomics 6:120.

Brito, L. F. C., A. E. D. F. Silva, L. H. Rodrigues, F. V. Vieira, L. A. G. Deragon, and J. P. Kastelic. 2002. Effects of environmental factors, age and genotype on sperm production and semen quality in Bos indicus and Bos taurus AI bulls in Brazil. Anim. Reprod. Sci. 70:181-190.

Chang, T.C., Y. Yang, E. F. Retzel, and W.-S. Liu. 2013. The malespecific region of the bovine $\mathrm{Y}$ chromosome is gene-rich with a high transcriptomic activity in testis development. Proc. Natl. Acad. Sci. USA 110:12373-12378.

Chang, T.-C., Y. Yang, H. Yasue, A. K. Bharti, E. F. Retzel, and W.-S. Liu. 2011a. The expansion of the PRAME gene family in Eutheria. PLoS ONE 6:e16867.

Chang, Z. H., L. Wei, R. Zhang, B. Guo, C. He, X. Lan, H. Chen, and C. Lei. 2011b. Genetic diversity and origin based on Y-SNPs in Chinese cattle. Acta Vet. Zootec. Sin. 42:1537-1542.

Church, D. M., L. Goodstadt, L. W. Hillier, M. C. Zody, S. Goldstein, X. She, C. J. Bult, R. Agarwala, J. L. Cherry, M. DiCuccio, W. Hlavina, Y. Kapustin, P. Meric, D. Maglott, Z. Birtle,
A. C. Marques, T. Graves, S. Zhou, B. Teague, K. Potamousis, C. Churas, M. Place, J. Herschleb, R. Runnheim. D. Forrest, J. Amos-Landgraf, D. C. Schwartz, Z. Cheng, K. Lindblad-Toh, E. E. Eichler, C. P. Ponting, and The Mouse Genome Sequencing Consortium. 2009. Lineage-specific biology revealed by a finished genome assembly of the mouse. PLoS Biol. 7:e1000112.

Cocquet, J., P. J. I. Ellis, Y. Yamauchi, S. K. Mahadevaiah, N. A. Affara, M. A. Ward, and P. S. Burgoyne. 2009. The multicopy gene Sly represses the sex chromosomes in the male mouse germline after meiosis. PLoS Biol. 7:e1000244.

Coulter, G. H., and R. H. Foote. 1976. Relationship of testicular weight to age and scrotal circumference of Holstein bulls. J. Dairy Sci. 59:730-732.

Coulter, G. H., R. J. Mapletoft, G. C. Kozub, and W. F. Cates. 1987. Scrotal circumference of two-year-old bulls of several beef breeds. Theriogenology 27:485-491.

Di Meo, G. P., A. Perucatti, S. Floriot, D. Incarnato, R. Rullo, A. C. Jambrenghi, L. Ferretti, G. Vonghia, E. Cribiu, A. Eggen, and L. Iannuzzi. 2005. Chromosome evolution and improved cytogenetic maps of the Y chromosome in cattle, zebu, river buffalo, sheep and goat. Chromosome Res. 13:349-355.

Dunn, O. J. 1961. Multiple comparisons among means. J. Am. Stat. Assoc. 56:52-64.

Epping, M. T., L. Wang, M. J. Edel, L. Carlée, M. Hernandez, and R. Bernards. 2005. The human tumor antigen PRAME is a dominant repressor of retinoic acid receptor signaling. Cell 122:835-847.

Foresta, C., E. Moro, and A. Ferlin. 2001. Y chromosome microdeletions and alterations of spermatogenesis. Endocr. Rev. 22:226239.

Giachini, C., F. Nuti, D. J. Turner, I. Laface, Y. Xue, F. Daguin, G. Forti, C. Tyler-Smith, and C. Krausz. 2009. TSPY1 copy number variation influences spermatogenesis and shows differences among Y lineages. J. Clin. Endocrinol. Metab. 94:4016-4022.

Gibbs, R. A., J. F. Taylor, C. P. Van Tassell, W. Barendse, K. A. Eversole, C. A. Gill, R. D. Green, D. L. Hamernik, S. M. Kappes, S. Lien, L. K. Matukumalli, J. C. McEwan, L. V. Nazareth, R. D. Schnabel, G. M. Weinstock, D. A. Wheeler, P. Ajmone-Marsan, P. J. Boettcher, A. R. Caetano, J. F. Garcia, O. Hanotte, P. Mariani, L. C. Skow, T. S. Sonstegard, J. L. Williams, B. Diallo, L. Hailemariam, M. L. Martinez, C. A. Morris, L. O. C. Silva, R. J. Spelman, W. Mulatu, K. Zhao, C. A. Abbey, M. Agaba, F. R. Araujo, R. J. Bunch, J. Burton, C. Gorni, H. Olivier, B. E. Harrison, B. Luff, M. A. Machado, J. Mwakaya, G. Plastow, W. Sim, T. Smith, M. B. Thomas, A. Valentini, P. Williams, J. Womack, J. A. Woolliams, Y. Liu, X. Qin, K. C. Worley, C. Gao, H. Jiang, S. S. Moore, Y. Ren, X.-Z. Song, C. D. Bustamante, R. D. Hernandez, D. M. Muzny, S. Patil, A. San Lucas, Q. Fu, M. P. Kent, R. Vega, A. Matukumalli, S. McWilliam, G. Sclep, K. Bryc, J. Choi, H. Gao, J. J. Grefenstette, B. Murdoch, A. Stella, R. Villa-Angulo, M. Wright, J. Aerts, O. Jann, R. Negrini, M. E. Goddard, B. J. Hayes, D. G. Bradley, M. Barbosa da Silva, L. P. L. Lau, G. E. Liu, D. J. Lynn, F. Panzitta, and K. G. Dodds. 2009. Genomewide survey of SNP variation uncovers the genetic structure of cattle breeds. Science 324:528-532.

Goldammer, T., R. M. Brunner, and M. Schwerin. 1997. Comparative analysis of Y chromosome structure in Bos taurus and B. indicus by FISH using region-specific, microdissected, and locus-specific DNA probes. Cytogenet. Cell Genet. 77:238-241.

Hamilton, C. K., L. A. Favetta, G. P. Di Meo, S. Floriot, A. Perucatti, J. Peippo, J. Kantanen, A. Eggen, L. Iannuzzi, and W. A. King. 2009. Copy number variation of testis-specific protein, Y-encoded (TSPY) in 14 different breeds of cattle (Bos taurus). Sex Dev. 3:205-213.

Hamilton, C. K., T. Revay, R. Domander, L. A. Favetta, and W. A. King. 2011. A large expansion of the $H S F Y$ gene family in cattle shows dispersion across $\mathrm{Yq}$ and testis-specific expression. PLoS ONE 6:e17790.

Hamilton, C. K., A. R. Verduzco-Gómez, L. A. Favetta, P. Blondin, and W. A. King. 2012. Testis-specific protein Y-encoded copy number is correlated to its expression and the field fertility of Canadian Holstein bulls. Sex Dev. 6:231-239. 
Justel, A., D. Peña, and R. Zamar. 1997. A multivariate KolmogorovSmirnov test of goodness of fit. Stat. Probab. Lett. 35:251-259.

Kapustin, Y., A. Souvorov, T. Tatusova, and D. Lipman. 2008. Splign: Algorithms for computing spliced alignments with identification of paralogs. Biol. Direct 3:20. http://dx.doi.org/10.1186/17456150-3-20.

Kastner, P., M. Mark, M. Leid, A. Gansmuller, W. Chin, J. M. Grondona, D. Décimo, W. Krezel, A. Dierich, and P. Chambon. 1996. Abnormal spermatogenesis in RXR beta mutant mice. Genes Dev. 10:80-92.

Kleiman, S. E., L. Yogev, E. N. Gal-Yam, R. Hauser, R. Gamzu, A. Botchan, G. Paz, H. Yavetz, B. B.-S. Maymon, L. Schreiber, S. Barzilai, N. Amariglio, G. Rechavi, and A. J. Simon. 2003. Reduced human germ cell-less (HGCL) expression in azoospermic men with severe germinal cell impairment. J. Androl. 24:670-675.

Krausz, C. 2005. Y chromosome and male infertility. Andrologia $37: 219-223$.

Krausz, C., and S. Degl'Innocenti. 2006. Y chromosome and male infertility: Update, 2006. Front. Biosci. 11:3049-3061.

Krausz, C., G. Forti, and K. McElreavey. 2003. The Y chromosome and male fertility and infertility. Int. J. Androl. 26:70-75.

Krausz, C., C. Giachini, and G. Forti. 2010. TSPY and male fertility. Genes 1:308-316.

Lahn, B. T., and D. C. Page. 1997. Functional coherence of the human Y chromosome. Science 278:675-680.

Lahn, B. T., and D. C. Page. 1999. Retroposition of autosomal mRNA yielded testis-specific gene family on human Y chromosome. Nat. Genet. 21:429-433

Lahn, B. T., N. M. Pearson, and K. Jegalian. 2001. The human Y chromosome, in the light of evolution. Nat. Rev. Genet. 2:207-216.

Lin, Y.-W., D. A. D. Thi, P.-L. Kuo, C.-C. Hsu, B.-D. Huang, Y.-H Yu, P. H. Vogt, W. Krause, A. Ferlin, C. Foresta, T. Bienvenu, W. Schempp, and P. H. Yen. 2005. Polymorphisms associated with the $D A Z$ genes on the human Y chromosome. Genomics 86:431-438.

Mann, H. B., and D. R. Whitney. 1947. On a test of whether one of two random variables is stochastically larger than the other. Ann. Math. Stat. 18:50-60.

Mannen, H. 2011. Identification and utilization of genes associated with beef qualities. Anim. Sci. J. 82:1-7.

Mistry, B. V., Y. Zhao, T.-C. Chang, H. Yasue, M. Chiba, J. Oatley, F. Diaz, and W.-S. Liu. 2013. Differential expression of PRAMEL1, a cancer/testis antigen, during spermatogenesis in the Mouse. PLoS ONE 8:e60611.

Nickkholgh, B., M. J. Noordam, S. E. Hovingh, A. M. M. van Pelt, F. van der Veen, and S. Repping. 2010. Y chromosome TSPY copy numbers and semen quality. Fertil. Steril. 94:1744-1747.

Ortmann, C. A., L. Eisele, H. Nückel, L. Klein-Hitpass, A. Führer, U. Dührsen, and M. Zeschnigk. 2008. Aberrant hypomethylation of the cancer-testis antigen PRAME correlates with PRAME expression in acute myeloid leukemia. Ann. Hematol. 87:809-818.

Parkinson, T. J. 2004. Evaluation of fertility and infertility in natural service bulls. Vet. J. 168:215-229.

Poongothai, J., T. S. Gopenath, and S. Manonayaki. 2009. Genetics of human male infertility. Singapore Med. J. 50:336-347.

Reynard, L. N., J. Cocquet, and P. S. Burgoyne. 2009. The multi-copy mouse gene Sycp3-like Y-linked (Sly) encodes an abundant spermatid protein that interacts with a histone acetyltransferase and an acrosomal protein. Biol. Reprod. 81:250-257.

Schuster-Böckler, B., D. Conrad, and A. Bateman. 2010. Dosage sensitivity shapes the evolution of copy-number varied regions. PLoS ONE 5:e9474.

Shapiro, S. S., and M. B. Wilk. 1965. An analysis of variance test for normality (complete samples). Biometrika 52:591-611.

Skaletsky, H., T. Kuroda-Kawaguchi, P. J. Minx, H. S. Cordum, L. Hillier, L. G. Brown, S. Repping, T. Pyntikova, J. Ali, T. Bieri A. Chinwalla, A. Delehaunty, K. Delehaunty, H. Du, G. Fewell, L. Fulton, R. Fulton, T. Graves, S.-F. Hou, P. Latrielle, S. Leonard, E. Mardis, R. Maupin, J. McPherson, T. Miner, W. Nash, C. Nguyen, P. Ozersky, K. Pepin, S. Rock, T. Rohlfing, K. Scott, B Schultz, C. Strong, A. Tin-Wollam, S.-P. Yang, R. H. Waterston, R. K. Wilson, S. Rozen, and D. C. Page. 2003. The male-specific region of the human $\mathrm{Y}$ chromosome is a mosaic of discrete sequence classes. Nature 423:825-837.

Stranger, B. E., M. S. Forrest, M. Dunning, C. E. Ingle, C. Beazley, N. Thorne, R. Redon, C. P. Bird, A. de Grassi, C. Lee, C. TylerSmith, N. Carter, S. W. Scherer, S. Tavaré, P. Deloukas, M. E. Hurles, and E. T. Dermitzakis. 2007. Relative impact of nucleotide and copy number variation on gene expression phenotypes. Science 315:848-853.

Tamura, K., D. Peterson, N. Peterson, G. Stecher, M. Nei, and S. Kumar. 2011. MEGA5: Molecular evolutionary genetics analysis using maximum likelihood, evolutionary distance, and maximum parsimony methods. Mol. Biol. Evol. 28:2731-2739.

VanRaden, P. M., C. P. Van Tassell, G. R. Wiggans, T. S. Sonstegard R. D. Schnabel, J. F. Taylor, and F. S. Schenkel. 2009. Invited review: Reliability of genomic predictions for North American Holstein bulls. J. Dairy Sci. 92:16-24.

Vodicka, R., R. Vrtel, L. Dusek, A. R. Singh, K. Krizova, V. Svacinova, V. Horinova, J. Dostal, I. Oborna, J. Brezinova, A. Sobek, and J. Santavy. 2007. TSPY gene copy number as a potential new risk factor for male infertility. Reprod. Biomed. Online 14:579-587.

Yang, Y., T.-C. Chang, H. Yasue, A. K. Bharti, E. F. Retzel, and W.-S. Liu. 2011. ZNF280BY and ZNF280AY: Autosome derived Y-chromosome gene families in Bovidae. BMC Genomics 12:13. 